\section{Improving Rooting and Shoot Tip Survival of Micropropagated Transgenic American Chestnut Shoots}

\author{
Allison D. Oakes ${ }^{1}$, Tyler Desmarais, William A. Powell, \\ and Charles A. Maynard \\ State University of New York College of Environmental Science and Forestry, \\ 1 Forestry Drive, 217 Marshall Hall, Syracuse, NY 13210
}

Additional index words. Castanea dentata, Cryphonectria parasitica, micropropagation, tissue culture

\begin{abstract}
Many hardwood tree species are being threatened by exotic pests, and for some, only genetic engineering can offer a solution before functional extinction occurs. An example of how genetic engineering can be a useful tool for forest restoration is the transgenic american chestnuts, which contain a wheat oxalate oxidase gene conferring resistance to the chestnut blight. Many hundreds of these trees are needed for field trials and eventual restoration plantings throughout its natural range, but production is bottlenecked because of the difficulty of making hardwood trees produce roots through micropropagation. The presence of roots and living shoot tips precede successful acclimatization of tissue culture-produced american chestnut plantlets. In these experiments, we attempted to improve the post-rooting stage of our american chestnut propagation protocol. We examined vessel type, hormone, and activated charcoal concentrations, and using a vermiculite substrate. For plantlets with the best combination of roots and living shoot tips we recommend using semisolid post-rooting medium containing $2 \mathrm{~g} \cdot \mathrm{L}^{-1}$ activated charcoal and $500 \mathrm{mg}$ humic acid in disposable fast-food takeout containers. When using vermiculite as a substrate, adding $2.0 \mathrm{~g} \cdot \mathrm{L}^{-1}$ activated charcoal to post-rooting medium without a gelling agent was the preferred treatment. Improving the survival rates of the american chestnut plantlets will benefit the american chestnut restoration project by providing more plant material for both ecological studies and eventual restoration, since pursuit of a nonregulated status for these transgenic trees will require extensive field testing. These procedures may also be applicable to other difficult-to-root hardwood trees in transgenic programs, such as american butternut, white oak, and black walnut.
\end{abstract}

The american chestnut was once a cornerstone of hardwood forests as far north as Maine and Ontario and as far south as Georgia and Mississippi, and once covered 200 million acres of land (Saucier, 1973). Not only did this tree have an extensive range, but it also grew to huge proportions, reaching heights of $60-90 \mathrm{ft}$ and diameters of $6-7 \mathrm{ft}$ (Brooks, 1937; Saucier, 1973). American chestnuts comprised up to $25 \%$ of the timber volume in Appalachian forests and the versatile and rotresistant wood was used for telegraph and telephone poles, mine props, railroad ties, rail fences, shingles, and barn construction (Brooks, 1937). Chestnut seed fed turkeys, deer, black bears, and local residents every autumn and were an important cash crop for the Appalachian region (Freinkel, 2009; Hepting, 1974). The once massive canopy tree is now relegated to a rare understory shrub.

The fungus that causes the chestnut blight, Cryphonectria parasitica, arrived in New York in the late 1800s aboard a shipment of imported Asiatic chestnut trees (Griffin, 2000). The disease was first documented on

Received for publication 4 Sept. 2015. Accepted for publication 14 Oct. 2015 .

${ }^{1}$ Corresponding author. E-mail: adoakes@syr.edu. dying american chestnuts in the Bronx Zoo in 1904 and spread rapidly throughout the Eastern United States over the next 30 years, wiping out billions of mature canopy trees (Murrill, 1906). The fungus secretes oxalate, which kills the cambium cells and lowers the $\mathrm{pH}$ to 2.8 at the canker margins (McCarroll and Thor, 1978), making it impossible for the tree to sequester the infection. The canker grows unchecked in the cambium, eventually girdling the stem and killing the tree (Cessna et al., 2000; Schlarbaum et al., 1997). The trees can resprout from the root collar, but are killed back by blight before growing old enough to reproduce.

Genetic engineering is poised to offer a solution: blight-resistant american chestnut trees. The addition of one gene, oxalate oxidase, can protect the american chestnut by breaking down the oxalic acid secreted by the fungus (Zhang et al., 2013). The fungus still infects wounds in the bark, but after the initial infection the tree halts the spread behind a wound periderm and fungus cannot spread further (Newhouse et al., 2014).

Many oxalate oxidase-expressing lines of transgenic american chestnuts are currently in production, developed by an Agrobacteriummediated transformation (Polin et al., 2006). Many trees from each line are needed for field trials and ecological impact studies to assess their safety and nontarget environmental effects, such as mycorrhizae formation (D'Amico et al., 2014). Wild-type american chestnuts derived from tissue culture are important controls and are also needed in large numbers.

Producing hardwood trees from tissue culture is an extremely time- and laborintensive process, requiring many steps and different growing media (Gonçalves et al., 1998; Gonzalez Padilla et al., 2003; Pijut et al., 2010). The main production bottleneck for micropropagated american chestnuts are the rooting and acclimatization stages, where shoots are excised from callus, dipped in a rooting hormone, placed in a low-salt medium in the dark, moved to a postrooting medium on a light bench, and finally potted in soil in high humidity bins. Plantlets that survive this process are moved to individual pots and have a high survival rate in high-humidity growth chambers and finally the greenhouse. Sometimes over $50 \%$ of shoots are lost in each stage, with acclimatization success as low as $10 \%$ of all shoots initially entering the rooting process.

Our research has been addressing this bottleneck by investigating improvements to our rooting protocol. A previous study found that plantlet survival in the growth chambers could be dramatically improved by shortening the time in rooting medium from $8-10 \mathrm{~d}$ to $3-4 \mathrm{~d}$, and also by placing plantlets in the dark during that time (Oakes et al., 2013). In addition, acclimatization success can generally be improved by increasing the number of adventitious roots produced in culture and keeping the shoot tip of the plantlet alive (Vieitez et al., 1989; Xing et al., 1997). It is also advised to only root larger plantlets with more leaves to ensure acclimatization success, as leaves produce important rooting cofactors (Macdonald, 2006; Oakes et al., 2013).

There are numerous factors which can affect rooting of micropropagated shoots. Activated charcoal is commonly used in plant tissue culture to darken the medium, but has the undesired effect of binding growth regulators and rendering them unavailable to the plant (Nissen and Sutter, 1990). It is generally added after auxin has been applied because of its inhibitory properties (Dumas and Monteuuis, 1995; Le Roux and Staden, 1991; McCown and McCown, 1987). We examined whether a concentration of activated charcoal lower than our standard $2 \mathrm{~g} \cdot \mathrm{L}^{-1}$ would still enhance root production.

Vessel type can have an impact on culture growth as well, by changing the rate of gas exchange and amount of oxygen available for respiration (Bateson et al., 1987). For three woody plant species, larger container size was found to increase rooting (McClelland and Smith, 1990). Ventilation helps reduce the relative humidity of the culture container to below $100 \%$, encouraging transpiration (Gribble, 1999). We chose to examine whether using large clear plastic takeout containers in place of vented Magenta GA-7 
vessels would influence root formation and shoot tip survival.

The addition of vermiculite, a textured substrate, to rooting medium was found to improve root induction in multiple hardwood species, including walnut (Vahdati et al., 2004), papaya (Kaity et al., 2009), and pear (Tetsumura et al., 2011). Vermiculitecontaining medium also enhanced root morphogenesis in ginger and ginseng (Inden et al., 1988; Malamug et al., 1991; Shoyama et al., 1995), and improves rooting and root quality in specific apple cultivars (Druart, 1997; Navatel and Bourrain, 1994). We examined whether a gelling agent (phytagel) or activated charcoal were necessary when using vermiculite for rooting american chestnut shoots.

Humic acids have been investigated as an additive to plant tissue culture because of their auxin-like activity (Cacco and Dell'agnola, 1984; Dell'Agnola and Nardi, 1987; Muscolo et al., 1999, 2007), chelating abilities (Ouni et al., 2014), and influence on root architecture (Trevisan et al., 2010). The addition of these compounds to growing medium has been shown to increase leaf and shoot growth in young seedlings (Piccolo et al., 1993) and stimulate cell growth and development (Nardi et al., 2002).

This series of experiments focused on improving root production and shoot tip survival by modifying the post-rooting medium. We tested activated charcoal concentrations, vessel type, humic acid concentration, and parameters for using a vermiculite substrate.

\section{Methods}

Plant material. For these experiments, we used american chestnut shoot cultures of wild type and transgenic lines, all derived from parent clone Ellis no. 1. Ellis no. 1 is a wildtype somatic embryo line started at State University of New York College of Environmental Science and Forestry from immature burrs donated by the New York chapter of The American Chestnut Foundation collected from a pure american chestnut tree in New York State. Embryo cultures were transformed via an Agrobacterium-mediated transformation protocol and regenerated to axillary shoot cultures (Maynard et al., 2014; Polin et al., 2006), including a nontransformed control. Shoot cultures were maintained in Magenta GA-7 vessels with vented lids containing pre-rooting medium consisting of full-strength Lloyd and McCown woody plant medium (WPM) salts, $109 \mathrm{mg} \cdot \mathrm{L}^{-1}$ Nitsch \& Nitsch vitamins, $2.3 \mathrm{~mm} 2$-( $N$-morpholino)ethanesulfonic acid (MES), $12.5 \mu \mathrm{M}$ polyvinylpyrrolidone 40,000 MW (PVP-40), $0.22 \quad \mu \mathrm{M}$ benzylaminopurine (BA), $30 \mathrm{~g} \cdot \mathrm{L}^{-1}$ sucrose, $3.5 \mathrm{~g} \cdot \mathrm{L}^{-1}$ Phytagel, and $\mathrm{pH}$ adjusted to 5.5. Each vessel contained nine shoots. The vessels were kept on a light bench with a 16-h photoperiod at a light intensity of $31 \mu \mathrm{mol} \cdot \mathrm{m}^{-2} \cdot \mathrm{s}^{-1}$ for at least 6 weeks, or 2 transfers cycles, before the rooting and post-rooting treatments were applied.
In vitro rooting procedure. Shoots chosen for experimentation were required to have a minimum height of $3 \mathrm{~cm}$, at least 6 leaves, and at least one leaf $<1 \mathrm{~cm}$ in length as recommended by previous study (Oakes et al., 2013). Shoots were removed from the pre-rooting medium and excised from the basal callus. The basal end was cut at a $30^{\circ}$ angle from vertical to increase the exposed surface area of the vascular tissue. The shoots
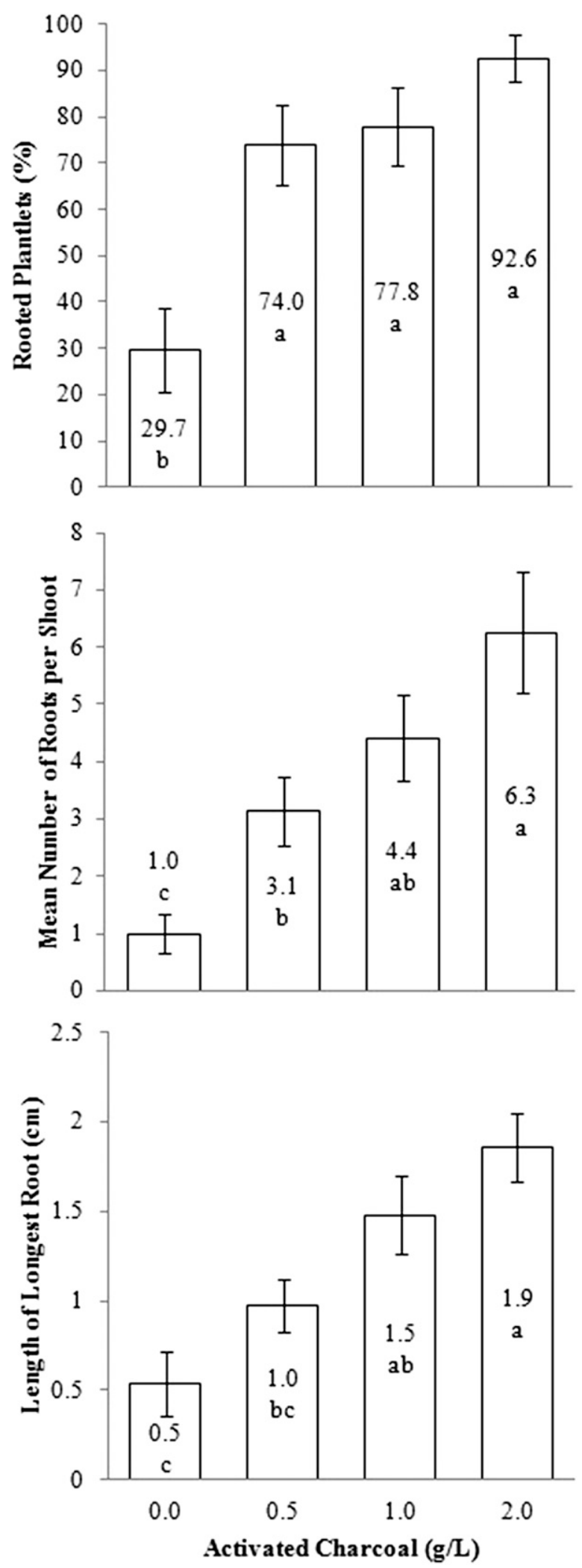

Fig. 1. Mean percent rooting, mean number of roots per plant, and length of longest root by activated charcoal concentrations. Treatments with different letters are significantly different at $\alpha=0.05$ using the Waller-Duncan K-ratio $t$ test. Error bars indicate SE of the mean. 
were then dipped into a $10 \mathrm{~mm}$ indole-3butyric acid (IBA) solution (203 mg IBA dissolved in $2 \mathrm{~mL} 1 \mathrm{M} \mathrm{KOH}$ and brought to total volume of $100 \mathrm{~mL}$ with distilled water). Shoots were placed into "clams," clear hinged containers (Dart Solo C53PST1 5 3/ $8^{\prime \prime} \times 51 / 4^{\prime \prime} \times 25 / 8^{\prime \prime}$ ClearSeal Clear Hinged Lid Plastic Container; Webstaurant Store Food Service Equipment and Supply Company, Lancaster, PA) containing rooting medium, consisting of half-strength Murashige and Skoog Basal Salt Mixture, 3\% sucrose, $3.5 \mathrm{~g} \cdot \mathrm{L}^{-1}$ Phytagel, and $\mathrm{pH}$ was adjusted to 5.5. The containers were placed in a dark cabinet at room temperature for 3-4 d. The shoots were used for the post-rooting experiments in post-rooting medium consisting of full-strength Lloyd and McCown WPM salts, $109 \mathrm{mg} \cdot \mathrm{L}^{-1}$ Nitsch \& Nitsch vitamins, (MES, $12.5 \mu \mathrm{M}$ PVP-40, $0.22 \mu \mathrm{M}$ BA, $30 \mathrm{~g} \cdot \mathrm{L}^{-1}$ sucrose, 3.5 g. $\mathrm{L}^{-1}$ Phytagel, $2 \mathrm{~g} \cdot \mathrm{L}^{-1}$ activated charcoal (autoclaved separately), and $\mathrm{pH}$ was adjusted to 5.5 .

Expt. 1: Activated charcoal concentrations. We tested four concentrations of activated charcoal $\left(0.0,0.5,1.0\right.$, and $2.0 \mathrm{~g} \cdot \mathrm{L}^{-1}$, autoclaved separately and added to $55^{\circ} \mathrm{C}$ medium before pouring) in the post-rooting medium. Three event line blocks of nine shoots were used for each of eight treatments for a total of 216 plantlets. Shoots were removed from the rooting medium and placed into the postrooting medium and on a light bench with a 16-h photoperiod at a light intensity of $31 \mu \mathrm{mol} \cdot \mathrm{m}^{-2} \cdot \mathrm{s}^{-1}$ for $8 \mathrm{~d}$, after which root presence, number of roots, length of longest root, and shoot tip survival were recorded.

Expt. 2: Culture vessel. Over the course of several production cycles between September and November of 2014 we split the plantlets between types of culture vessels, using either "cubes," Magenta GA-7 vessels with vented lids, or "clams," clear hinged takeout containers. All vessels were placed on a light bench with a 16-h photoperiod at a light intensity of $31 \mu \mathrm{mol} \cdot \mathrm{m}^{-2} \cdot \mathrm{s}^{-1}$ for $8 \mathrm{~d}$, after which we recorded root presence and shoot tip survival.

Expt. 3: Vermiculite substrate. Based on a pilot study (data not shown), we determined that using a vermiculite substrate could potentially yield better root systems than a traditional semisolid medium. In this experiment, we tested whether activated charcoal or a gelling agent was needed when using vermiculite as a substrate. We implemented a $2 \times 2$ factorial with activated charcoal $\left(0\right.$ or $\left.2 \mathrm{~g} \cdot \mathrm{L}^{-1}\right)$ and phytagel $(0$ or $\left.3.5 \mathrm{~g} \cdot \mathrm{L}^{-1}\right)$ contained in the post-rooting medium. Roughly, $80 \mathrm{~mL}$ of vermiculite was placed into Magenta GA-7 vessels and autoclaved separately. Post-rooting medium was then added to the containers of vermiculite and cooled in the hood before use. Four event line blocks of four plantlets of four treatments was repeated twice for a total of 128 plantlets. Plantlets were placed in each vessel and placed on a light bench with a $16-\mathrm{h}$ photoperiod at a light intensity of $31 \mu \mathrm{mol} \cdot \mathrm{m}^{-2} \cdot \mathrm{s}^{-1}$ for $8 \mathrm{~d}$, after which root presence, number of roots, and shoot tip survival were recorded.
Expt. 4: Humic acid. We implemented a $2 \times 5$ factorial with two concentrations of activated charcoal $\left(0.0\right.$ and $\left.2.0 \mathrm{~g} \cdot \mathrm{L}^{-1}\right)$ and four concentrations of humic acid $(0.0,50.0$, 100.0 , and $\left.500.0 \mathrm{mg} \cdot \mathrm{L}^{-1}\right)$ in post-rooting medium. Two event line blocks of six plantlets for eight treatments was repeated twice for a total of 192 plantlets. Clamshells were placed on a light bench with a 16 -h photoperiod at a light intensity of $31 \mu \mathrm{mol} \cdot \mathrm{m}^{-2} \cdot \mathrm{s}^{-1}$ for $8 \mathrm{~d}$, after which root presence, number of roots, and shoot tip survival were recorded.

Statistical analysis. In each experiment, the different event lines were treated as blocks in a randomized complete block design. The data for each experiment were analyzed using analysis of variance using $\mathrm{SAS}^{\mathrm{TM}} 9.0$ statistical software (SAS Institute Inc., Cary, NC); means were tested with Waller-Duncan K ratio $t$ tests.

\section{Results}

Expt. 1: Activated charcoal concentration. The presence of activated charcoal in postrooting medium significantly increased the percentage of rooted plantlets (Fig. 1A; $\mathrm{F}=$ $11.93, P$ value $<0.0001)$, but increasing the concentration did not significant affect root presence. Increasing the concentration of activated charcoal did have a significant effect on number of roots (Fig. 1B; $\mathrm{F}=9.07, P$ value $<$ 0.0001 ), and length of longest root (Fig. 1C; $\mathrm{F}=10.06, P$ value $=<0.0001)$. Shoot tip survival was less than $14 \%$ for all treatments and not statistically significant.

Expt. 2: Culture vessel. Using disposable clamshell takeout containers during postrooting significantly decreased the survival of shoot tips $(\mathrm{F}=4.39, P$ value $=0.0376)$, but significantly increased root formation $(\mathrm{F}=$ $11.8, P$ value $=0.0007)$ as shown in Fig. 2 . The dimensions of the cubes are $6 \mathrm{~cm} \times 6 \mathrm{~cm} \times$ $9.5 \mathrm{~cm}$, with a total volume of $342 \mathrm{~mL}$, of which $85 \mathrm{~mL}$ contains medium and $257 \mathrm{~mL}$ contains air (1:3). The dimensions of the clams are $11 \mathrm{~cm} \times 12 \mathrm{~cm} \times 7 \mathrm{~cm}$, with a total volume of $924 \mathrm{~mL}$, of which $166 \mathrm{~mL}$ contains medium and $758 \mathrm{~mL}$ contains air (1:4).

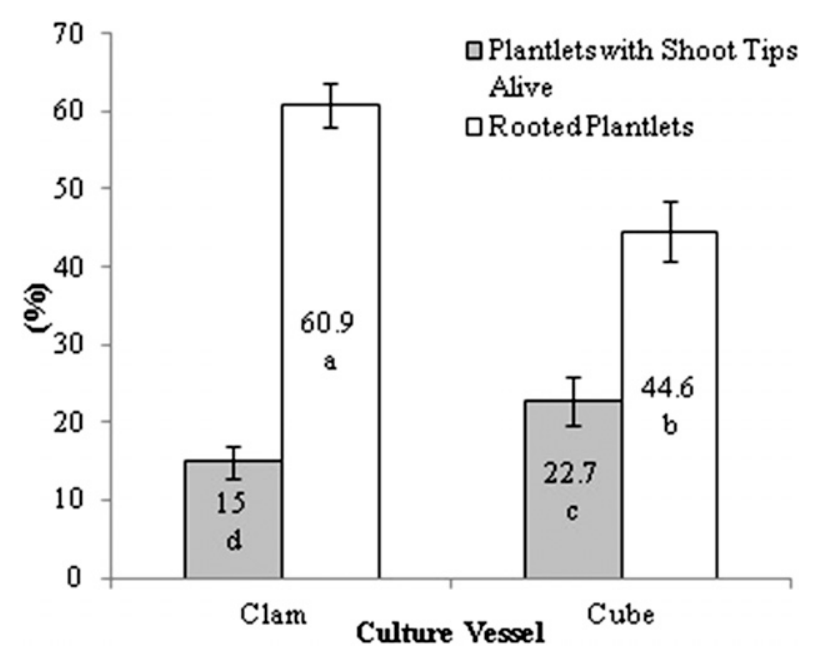

Fig. 2. Proportion of plantlets with living shoot tips or roots after post-rooting treatment in either disposable clamshell container or Magenta cubes. Treatments with different letters are significantly different at $\alpha=0.05$ using the Waller-Duncan K-ratio $t$ test. Error bars indicate SE of the mean.
Expt. 3: Vermiculite substrate. The presence of activated charcoal across vermiculite treatments increased root presence and number of roots while decreasing shoot tip survival. The treatments without activated charcoal had an average of $21.6 \%$ rooted plantlets $(\mathrm{F}=4.36, P$ value $=0.039), 0.59$ roots per plantlet $(\mathrm{F}=3.44, P$ value $=.035)$, and $44.6 \%$ living shoot tips $(\mathrm{F}=11.76$, $P$ value $=0.0008)$. The $2 \mathrm{~g} \cdot \mathrm{L}^{-1}$ activated charcoal treatments had an average of $35.8 \%$ rooted plantlets, 1.56 roots per plantlet, and $20.5 \%$ living shoot tips.

The presence of phytagel across vermiculite treatments resulted in lower root presence and fewer root number and had no effect on shoot tip survival. The treatments without phytagel had an average of $43.2 \%$ rooted plantlets $(\mathrm{F}=11.03$, $P$ value $=0.0012)$ and 1.6 roots per plantlet $(\mathrm{F}=$ $10.43, P$ value $=0.0016)$. The $3.5 \mathrm{~g} \cdot \mathrm{L}^{-1}$ phytagel treatments had an average of $16.4 \%$ rooted plantlets and 0.47 roots per plantlet.

The treatment means for root presence, number of roots, and shoot tip survival are shown in Fig. 3A-C.

Expt. 4: Humic acid. The high concentrations (100 and $\left.500 \mathrm{mg} \cdot \mathrm{L}^{-1}\right)$ of humic acid combined with $2 \mathrm{~g} \cdot \mathrm{L}^{-1}$ activated charcoal had excellent and significantly higher root presence than all the treatments without activated charcoal (Fig. 4A). This trend was similar when examining root number (Fig. 4B). Less difference was observed in shoot tip survival, with the $100 \mathrm{mg} \cdot \mathrm{L}^{-1}$ humic acid treatment without activated charcoal had a significant higher shoot tip survival percentage $(58.3 \%)$ than the $500 \mathrm{mg} \cdot \mathrm{L}^{-1}$ humic acid treatment without activated charcoal $(20.8 \%)$ and the $2 \mathrm{~g} \cdot \mathrm{L}^{-1}$ activated charcoal treatment without humic acid (12.5\%) (Fig. 4C).

\section{Discussion}

One overarching trend seen repeatedly throughout this suite of experiments was that activated charcoal enhanced root growth but slightly decreased shoot tip survival. Previous 

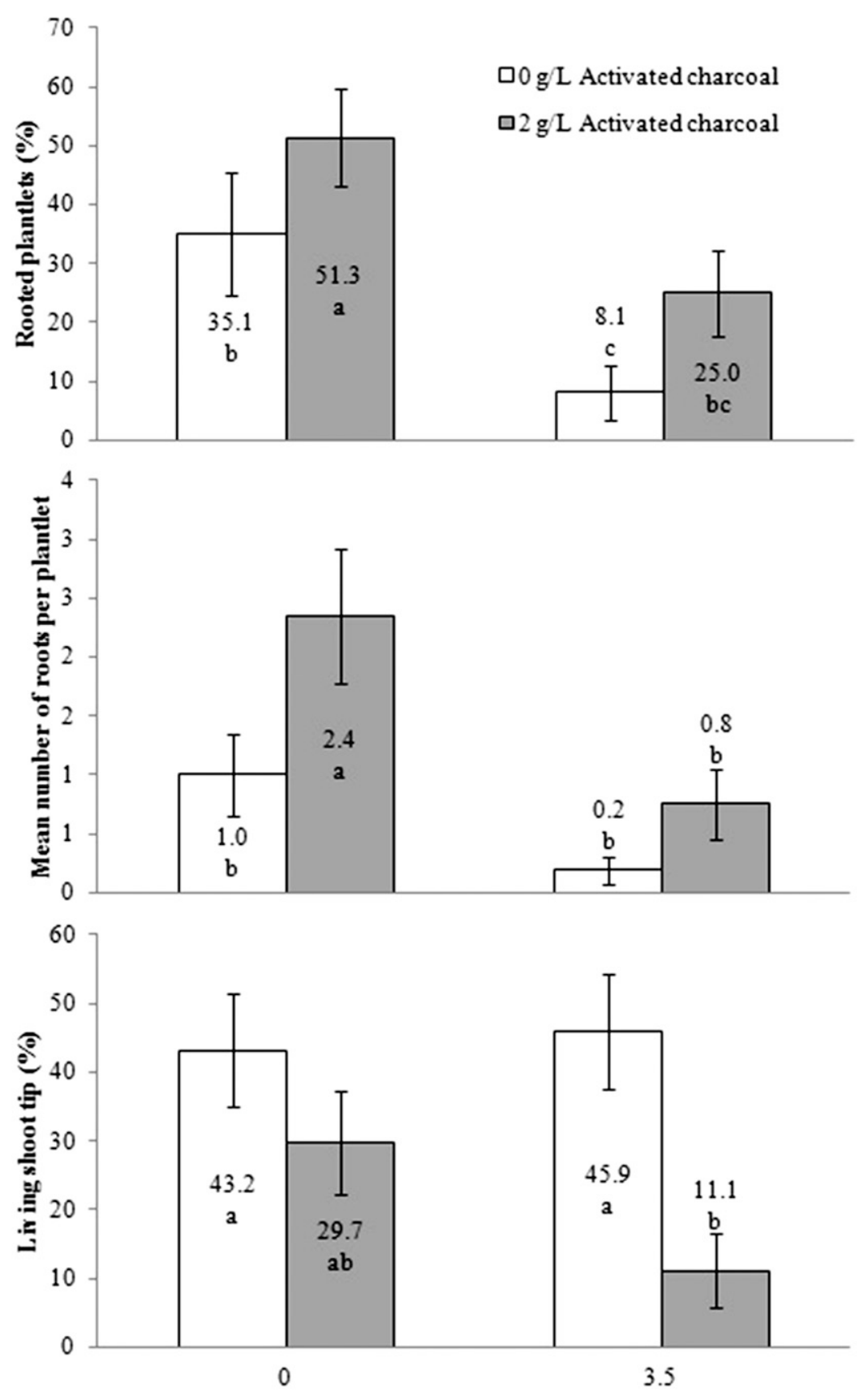

Phytagel Concentration in Vermiculite Substrate $(g / L)$

Fig. 3. Treatment means of rooting percentage, mean number of roots, and shoot tip survival by american chestnut plantlets in a vermiculite substrate during post-rooting. Treatments with different letters are significantly different at $\alpha=0.05$ using the Waller-Duncan K-ratio $t$ test. Error bars indicate SE of the mean.

work led us to believe that shoot tip survival was paramount to acclimatization success. However, improvements in prerooting propagation of large, healthy shoots have increased the chance that when the shoot tip dies, a healthy axillary bud will break and becomes the leader during acclimatization. This mode of sequential budbreak has been reported with some earlier work on rooting american chestnut (Serres et al., 1990). Healthier, larger plantlets are better able to withstand loss of the apical shoot tip than the shorter, smaller plantlets used in previous studies. Shoot health was a major factor in English and red oak and $10 \mathrm{~g} \cdot \mathrm{L}^{-1}$ ) were tested in a subsequent experiment, but root formation and shoot tip survival were not significantly different from the $2 \mathrm{~g} \cdot \mathrm{L}^{-1}$ treatment (data not shown).

Using disposable takeout containers, or "clams," has been advantageous for chestnut production thanks to the lower cost of buying containers compared with hiring labor to hand wash Magenta vessels. The significant increase in root production may be due to a larger surface area of activated charcoalcontaining medium in "clams," allowing for more efficient sequestration of ethylene (Pan and van Staden, 1998; Thomas, 2008); ethylene has been shown to inhibit root formation in vitro, and is absorbed by activated charcoal (Biddington, 1992; Coleman et al., 1980; Pierik et al., 2006). Increased medium surface area and a larger volume of air in the vessel might also allow for more accessible oxygen. The reduced shoot tip survival in "clams" is likely due to higher relative humidity compared with a vented vessel, known reduce transpiration.

The only time that secondary, forking roots were observed in any experiment was in the vermiculite substrate; production of secondary roots was also noted in similar experiments with walnut (Jay-Allemand et al., 1992). Increased aeration of the medium and a "rough" component of the vermiculite are thought to be responsible for the improvement in root development (Navatel and Bourrain, 1994).

The vermiculite method had high potential for root production but significantly increased the cost of plantlet production in both time and materials. In order for the vermiculite to be autoclaved it had to be measured into each individual cube before sterilization. Also, disposable takeout containers could not be used. This might be an interesting avenue of exploration for other hard-to-root species if simpler methods are not performing well. Future studies can investigate further with backcrossed american-chinese chestnut lines than have yet to root in vitro, as different varieties of the same species have been observed to have vastly different rooting preferences (Tetsumura et al., 2011), and also examine other procedures, which allow for the use of the disposable containers.

Other studies have found similar evidence for root promotion by humic acids. Lateral root emergence was promoted by earthwormderived humic acids in maize, due to increased tissue differentiation and cellular activity (Canellas et al., 2002). An increase in root morphogenesis is consistent with the observation that humic acids may mimic auxin mode of action (Atiyeh et al., 2002; Canellas et al., 2002). Increasing auxin concentrations in media is a classic method for increasing in vitro root production. Although high concentrations of auxin can inhibit primary root elongation, adventitious and lateral root formation are promoted (Aloni et al., 2006; Casimiro et al., 2001). The standard rooting procedure for many herbaceous species is to increase the concentration of auxin in the standard multiplication medium. However, 

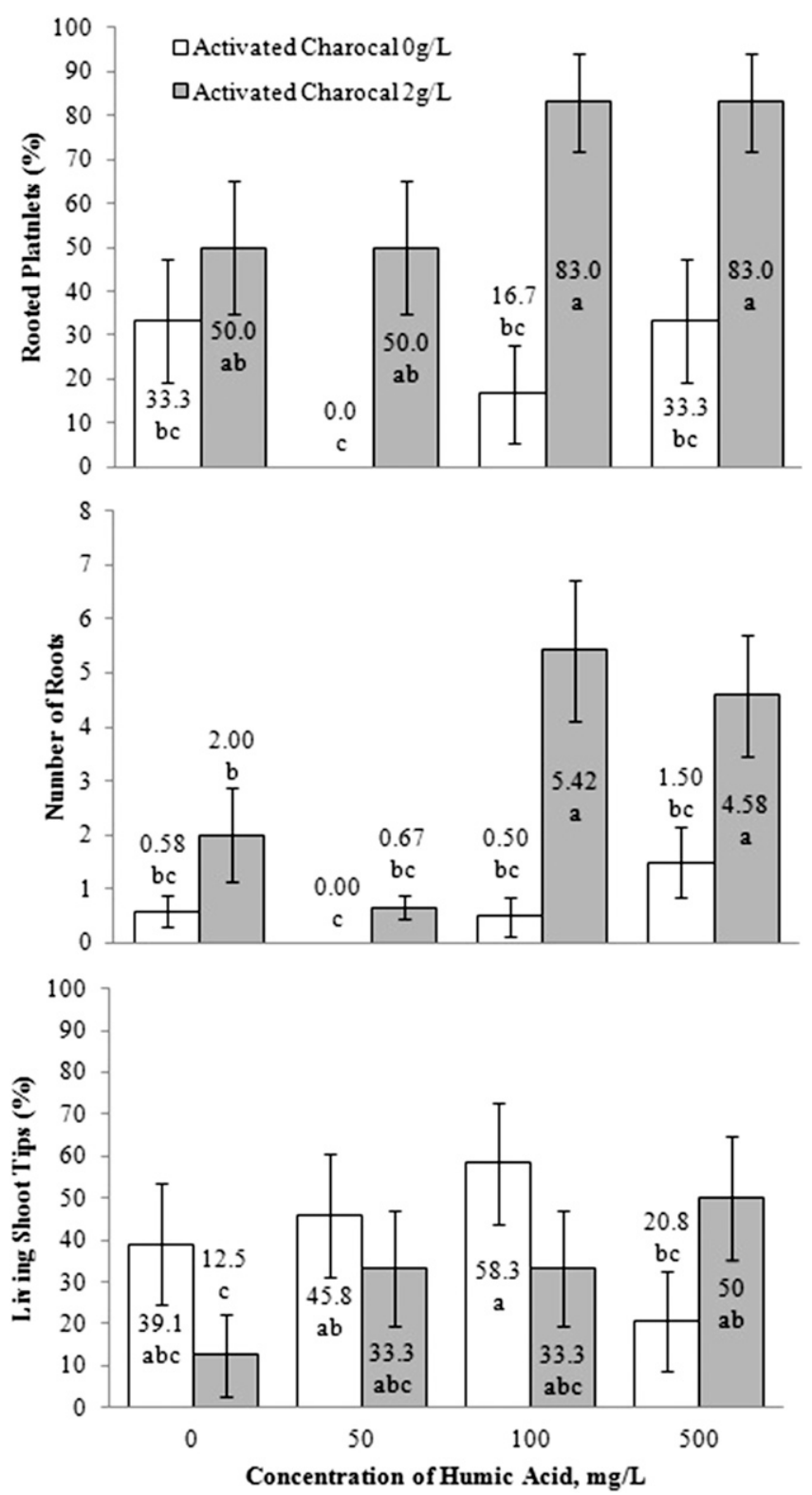

Fig. 4. Treatment means of rooting percentage, mean number of roots, and shoot tip survival by concentration of activated charcoal and humic acid. Treatments with different letters are significantly different at $\alpha=0.05$ using the Waller-Duncan K-ratio $t$ test. Error bars indicate SE of the mean.

activated charcoal absorbs copious amounts of auxin, sometimes leaving less than $1 \%$ of exogenous auxins available in the medium (Winkle and Pullman, 2005). Our results showed that a combination of activated charcoal $\left(2 \mathrm{~g} \cdot \mathrm{L}^{-1}\right)$ and humic acid (100 or $500 \mathrm{mg} \cdot \mathrm{L}^{-1}$ ) had a synergistic effect, producing more roots than either humic acid or activated charcoal alone.

\section{Conclusion}

Our findings have broad implications for tissue culture and genetic engineering of target hardwood species. The combination of humic acid and activated charcoal in rooting medium more than doubled the number of roots produced by micropropagated shoots than either compound alone. Vermiculite substrate may be an alternative with additional research and methods development. More blight-resistant american
Atiyeh, R.M., S. Lee, C.A. Edwards, N.Q. Arancon, and J.D. Metzger. 2002. The influence of humic acids derived from earthworm-processed organic wastes on plant growth. Bioresour. Technol. 84:7-14.

Bateson, J.M., B.W.W. Grout, and S. Lane. 1987. The influence of container dimensions in the multiplication rate of regenerating plant cell cultures, p. 275-277. In: Plant micropropagation in horticultural industries: Preparation, hardening and acclimatization Symposium. Belgian Plant Tissue Culture Group.

Biddington, N.L. 1992. The influence of ethylene in plant tissue culture. Plant Growth Regulat. 11:173-187.

Brooks, A.B. 1937. Castanea dentata. Castanea J. South. Appalach. Bot. Club 2:61-67.

Cacco, G. and G. Dell'agnola. 1984. Plant growth regulator activity of soluble humic complexes. Can. J. Soil Sci. 64:225-228.

Canellas, L.P., F.L. Olivares, A.L. OkorokovaFaçanha, and A.R. Façanha. 2002. Humic acids isolated from earthworm compost enhance root elongation, lateral root emergence, and plasma membrane $\mathrm{H}+$-ATPase activity in maize roots. Plant Physiol. 130:1951-1957.

Casimiro, I., A. Marchant, R.P. Bhalerao, T. Beeckman, S. Dhooge, R. Swarup, N. Graham, D. Inzé, G. Sandberg, P.J. Casero, and M. Bennett. 2001. Auxin transport promotes arabidopsis lateral root initiation. Plant Cell Online 13:843-852.

Cessna, S.G., V.E. Sears, M.B. Dickman, and P.S. Low. 2000. Oxalic acid, a pathogenicity factor for Sclerotinia sclerotiorum, suppresses the oxidative burst of the host plant. Plant Cell 12:2191-2200.

Coleman, W.K., T.J. Huxter, D.M. Reid, and T.A. Thorpe. 1980. Ethylene as an endogenous inhibitor of root regeneration in tomato leaf discs cultured in vitro. Physiol. Plant. 48:519-525.

D'Amico, K.M., T.R. Horton, C.A. Maynard, S.V. Stehman, A.D. Oakes, and W.A. Powell. 2014 Assessing ectomycorrhizal associations on transgenic american chestnut compared to the wild-type, a conventionally-bred hybrid, and related Fagaceae species. Appl. Environ. Microbiol. in review.

Dell'Agnola, G. and S. Nardi. 1987. Hormone-like effect and enhanced nitrate uptake induced by depolycondensed humic fractions obtained from Allolobophora rosea and A. caliginosa faeces. Biol. Fertil. Soils 4:115-118.

Druart, P. 1997. Optimization of culture media for in vitro rooting of Malus domestica Borkh. cv. Compact Spartan. Biol. Plant. 39:67-77.

Dumas, E. and O. Monteuuis. 1995. In vitro rooting of micropropagated shoots from juvenile and mature Pinus pinaster explants: Influence of activated charcoal. Plant Cell Tissue Organ Cult. 40:231-235

chestnuts need to be produced every yea for inoculation studies and ecological safety experiments, and investigating and rectifying production bottlenecks is paramount to the program's success.

With exotic pests invading North American forests, from thousand canker disease in Texan black walnut to sudden oak death in California, rapid response is crucial. Many species may not have 100 years for a resistance breeding program to bear fruit, and genetic engineering can only offer a solution if trees can make it from the laboratory into the forest.

\section{Literature Cited}

Aloni, R., E. Aloni, M. Langhans, and C.L. Ullrich. 2006. Role of cytokinin and auxin in shaping root architecture: Regulating vascular differentiation, lateral root initiation, root apical dominance and root gravitropism. Ann. Bot. 97:883-893
Freinkel, S. 2009. American chestnut: The life, death, and rebirth of a perfect tree. University of California Press, Berkeley, CA.

Griffin, G.J. 2000. Blight control and restoration of the american chestnut. J. For. 98:22-27.

Gonçalves, J.C., G. Diogo, and S. Amâncio. 1998. In vitro propagation of chestnut (Castanea sativa $\times$ C. crenata): Effects of rooting treatments on plant survival, peroxidase activity and anatomical changes during adventitious root formation. Sci. Hort. 72:265-275.

Gonzalez Padilla, I.M., K. Webb, and R. Scorza. 2003. Early antibiotic selection and efficient rooting and acclimatization improve the production of transgenic plum plants (Prunus domestica L.). Plant Cell Rep. 22:38-45.

Gribble, K. 1999. The influence of relative humidity on vitrification, growth and morphology of Gypsophila paniculata L. Plant Growth Regulat. 27:181-190. 
Hepting, G.H. 1974. Death of the american chestnut. J. For. Hist. 18:60-67.

Inden, H., T. Asahira, and A. Hirano. 1988. Micropropagation of ginger. Acta Hort ISHS 230:177-184.

Jay-Allemand, C., P. Capelli, and D. Cornu. 1992. Root development of in vitro hybrid walnut microcuttings in a vermiculite-containing gelrite medium. Sci. Hort. 51:335-342.

Kaity, A., A.M. Parisi, S.E. Ashmore, and R.A. Drew. 2009. Root initiation and acclimatization of papaya plants. Acta Hort ISHS 812:387-394.

Macdonald, B. 2006. Practical woody plant propagation for nursery growers. Timber Press, Portland, OR.

Malamug, J.J.F., H. Inden, and T. Asahira. 1991. Plantlet regeneration and propagation from ginger callus. Sci. Hort. 48:89-97.

Maynard, C.A., L.D. McGuigan, A.D. Oakes, B. Zhang, A.E. Newhouse, L.C. Northern, A.M. Chartrand, L.R. Will, K.M. Baier, and W.A. Powell. 2014. Chestnut, American (Castanea dentata (Marsh.) Borkh.) Chapter 13, p. 143-161. In: K. Wang (ed.). Methods in molecular biology. Third Edition: Agrobacterium Protocols. Springer, New York.

McCarroll, D.R. and E. Thor. 1978. The role of oxalic acid in the pathogenesis of Endothia parasitica. Am. Chestnut Proc. 1:60-63.

McClelland, M.T. and M. Smith. 1990. Vessel type, closure, and explant orientation influence in vitro performance of five woody species. HortScience 25:797-800.

McCown, D.D. and B.H. McCown. 1987. North American hardwoods, p. 247-260. In: J.M. Bonga and D.J. Durzan (eds.). Cell and tissue culture in forestry. Springer Netherlands. (Forestry Sciences).

Murrill, W.A. 1906. A serious chestnut disease. J. N. Y. Bot. Gard. 7:143-153.

Muscolo, A., F. Bovalo, F. Gionfriddo, and S. Nardi. 1999. Earthworm humic matter produces auxinlike effects on Daucus carota cell growth and nitrate metabolism. Soil Biol. Biochem. 31:1303-1311.

Muscolo, A., M. Sidari, O. Francioso, V. Tugnoli, and S. Nardi. 2007. The auxin-like activity of humic substances is related to membrane interactions in carrot cell cultures. J. Chem. Ecol. 33:115-129.

Nardi, S., D. Pizzeghello, A. Muscolo, and A. Vianello. 2002. Physiological effects of humic substances on higher plants. Soil Biol. Biochem. 34:1527-1536.

Navatel, J.C. and L. Bourrain. 1994. Influence of the physical structure of the medium on in vitro rooting. Adv. Hort. Sci. 8:57-59.
Newhouse, A.E., L.D. McGuigan, K.M. Baier, K.E. Valletta, W.H. Rottmann, T.J. Tschaplinski, C.A. Maynard, and W.A. Powell. 2014. Transgenic American chestnuts show enhanced blight resistance and transmit the trait to T1 progeny. Plant Sci. 288:88-97.

Nissen, S. and E. Sutter. 1990. Stability of IAA and IBA in nutrient medium to several tissue culture procedures. HortScience 25:800-802.

Oakes, A.D., W.A. Powell, and C.A. Maynard. 2013. Doubling acclimatization survival of micropropagated american chestnuts with darkness and shortened rooting induction time. J. Environ. Hort. 31:77-83.

Ouni, Y., T. Ghnaya, F. Montemurro, C. Abdelly, and A. Lakhdar. 2014. The role of humic substances in mitigating the harmful effects of soil salinity and improve plant productivity. Intl. J. Plant Prod. 8:353-374.

Pan, M.J. and J. van Staden. 1998. The use of charcoal in in vitro culture: A review. Plant Growth Regulat. 26:155-163.

Piccolo, A., G. Celano, and G. Pietramellara. 1993. Effects of fractions of coal-derived humic substances on seed germination and growth of seedlings (Lactuga sativa and Lycopersicum esculentum). Biol. Fert. Soils 16:11-15.

Pierik, R., D. Tholen, H. Poorter, E.J.W. Visser, and L.A.C.J. Voesenek. 2006. The Janus face of ethylene: Growth inhibition and stimulation. Trends Plant Sci. 11:176-183.

Pijut, P.M., K.E. Woeste, and C.H. Michler. 2010 Promotion of adventitious root formation of difficult-to-root hardwood tree species, p. 213251. In: J. Janick (ed.). Horticultural reviews. John Wiley \& Sons, Inc, Hoboken, NJ.

Polin, L.D., H. Liang, R.E. Rothrock, M. Nishii, D.L. Diehl, A.E. Newhouse, J.C. Nairn, W.A. Powell, and C.A. Maynard. 2006. Agrobacteriummediated transformation of American chestnut (Castanea dentata (Marsh.) Borkh.) somatic embryos. Plant Cell Tissue Organ Cult. 84:69-78.

Le Roux, J.J. and J.V. Staden. 1991. Micropropagation and tissue culture of Eucalyptus: A review. Tree Physiol. 9:435-477.

Rugini, E., A. Jacoboni, and M. Luppino. 1993. Role of basal shoot darkening and exogenous putrescine treatments on in vitro rooting and on endogenous polyamine changes in difficult-toroot woody species. Sci. Hort. 53:63-72.

Sanchez, M.C., M.C. San-Jose, A. Ballester, and A.M. Vieitez. 1996. Requirements for in vitro rooting of Quercus robur and Q. rubra shoots derived from mature trees. Tree Physiol. 16:673-680.

Saucier, J.R. 1973. American chestnut...an American wood (Castanea dentata (Marsh.)
Borkh.) FS-230. U.S. Department of Agriculture Forest Service, Washington, DC.

Schlarbaum, S.E., F. Hebard, P.C. Spaine, and J. C. Kamalay. 1997. Three American tragedies: Chestnut blight, butternut canker, and Dutch elm disease, p. 45-54. In: Exotic Pests of Eastern Forests Conference Proceedings. Nashville, TN

Serres, R., P. Read, W. Hackett, and P. Nissen. 1990. Rooting of American chestnut microcuttings. J. Environ. Hort. 8:86-88.

Shoyama, Y., X.X. Zhu, H. Matsushita, and H. Kishira. 1995. Somatic embryogenesis in ginseng (Panax Species), p. 343-356. In: P.D.Y.P.S. Bajaj (ed.). Somatic embryogenesis and synthetic seed II. Springer Verlag, Berlin, Heidelberg (Biotechnology in Agriculture and Forestry).

Tetsumura, T., A. Ishimura, Y. Aikou, N. Eguchi, Y. Kai, K. Tashiro, and C. Honsho. 2011. Vermiculite-containing and gellan gumsolidified medium improves rooting of microcuttings of Japanese pear cultivars. Acta Hort ISHS 923:59-64.

Thomas, T.D. 2008. The role of activated charcoal in plant tissue culture. Biotechnol. Adv 26:618-631.

Trevisan, S., O. Francioso, S. Quaggiotti, and S. Nardi. 2010. Humic substances biological activity at the plant-soil interface. Plant Signal. Behav. 5:635-643.

Vahdati, K., C. Leslie, Z. Zamani, and G. McGranahan. 2004. Rooting and acclimatization of in vitro-grown shoots from mature trees of three persian walnut cultivars. HortScience 39:324-327.

Vieitez, A.M., C. Sánchez, and C. San-José. 1989. Prevention of shoot-tip necrosis in shoot cultures of chestnut and oak. Sci. Hort. 41:151-159.

Winkle, S.C.V. and G.S. Pullman. 2005. Achieving desired plant growth regulator levels in liquid plant tissue culture media that include activated carbon. Plant Cell Rpt. 24:201-208.

Xing, Z., M.F. Satchwell, W.A. Powell, and C.A. Maynard. 1997. Micropropagation of American chestnut: Increasing rooting rate and preventing shoot-tip necrosis. In Vitro Cell. Dev. Biol. Plant 33:43-48.

Zhang, B., A.D. Oakes, A.E. Newhouse, K.M. Baier, C.A. Maynard, and W.A. Powell. 2013. A threshold level of oxalate oxidase transgene expression reduces Cryphonectria parasiticainduced necrosis in a transgenic American chestnut (Castanea dentata) leaf bioassay. Transgenic Res. 22:973-982. 